\title{
Tubulovillous adenoma arising 30 years after ileocystoplasty
}

\author{
P H King, D E Osborn, E H Mackay
}

\begin{abstract}
The possibility of recurrent colonic metaplasia occurring as a complication of pelvic ileal pouches after ileo-rectal anastomosis has been raised. Several reports have documented malignant bladder tumours developing in patients many years after an ileocystoplasty. The case of a 50 year old man, who developed a tubulovillous adenoma in the ileal patch 30 years after an ileocystoplasty had been performed to enlarge a tuberculous shrunken bladder, is reported. The adjacent small intestinal mucosa showed features suggestive of colonic metaplasia.
\end{abstract}

(₹ Clin Pathol 1992;45:928-929)

\section{Case report}

A 50 year old man initially presented in 1959 with haematuria and fever. After tuberculosis had been diagnosed he received chemotherapy, had an ileal augmentation cystoplasty for a shrunken bladder, and his pyonephrotic right kidney was resected.

He was referred to renal physicians in 1989 with recurrent attacks of dysuria and poor renal function. Apart from mild hypertension, routine clinical examination and blood tests were unremarkable. An intravenous pyelogram showed the presence of a hydronephrotic left kidney. A cystogram showed an irregular bladder (presumably due to his previous surgery) and free reflux of contrast fluid from the bladder into the left ureter and pelvicalyceal system. There was no evidence of a stenotic lesion or of tuberculosis. Cystoscopic examination showed a grossly distended bladder, with a superficial frond-like lesion $7.5 \mathrm{~mm}$ in diameter on the left lateral wall, which was endoscopically resected.

Microscopic examination of the specimen showed a mixture of tubular glands and fingerlike villi, lined by a mainly single layer of columnar mucin secreting cells. In some areas the epithelial cells showed mild nuclear hyperchromatism and evidence of stratification. Mitosis was absent. A small amount of normal urothelium was present. No normal ileal mucosa was identified. There was no evidence of in situ or invasive carcinoma. The appearances were those of a tubulovillous adenoma showing mild epithelial dysplasia (fig 1).

Histochemical studies using the high iron diamine-alcian blue technique showed that most of the goblet cell mucin present was of the sulphated colonic type.

Six months later a $1 \mathrm{~cm}$ nodule was resected endoscopically, and erythematous areas adjacent to this lesion and on the opposite bladder wall were biopsied. The histological appearances of the tumour were similar to that of the previous lesion. The biopsy specimens from the erythematous areas consisted of connective tissue, submucosa, and overlying glandular epithelium, comprising a single layer of columnar mucin screting cells. No normal ileal mucosa or urothelium were present. Sometimes the surface epithelium was partly villous, but elsewhere only very stunted villi were present. The underlying lamina propria contained a moderate chronic inflammatory cell infiltrate. There was no evidence of dysplasia. The appearances were those of atrophic small intestinal mucosa showing features suggestive of colonic metaplasia (fig 2 ).

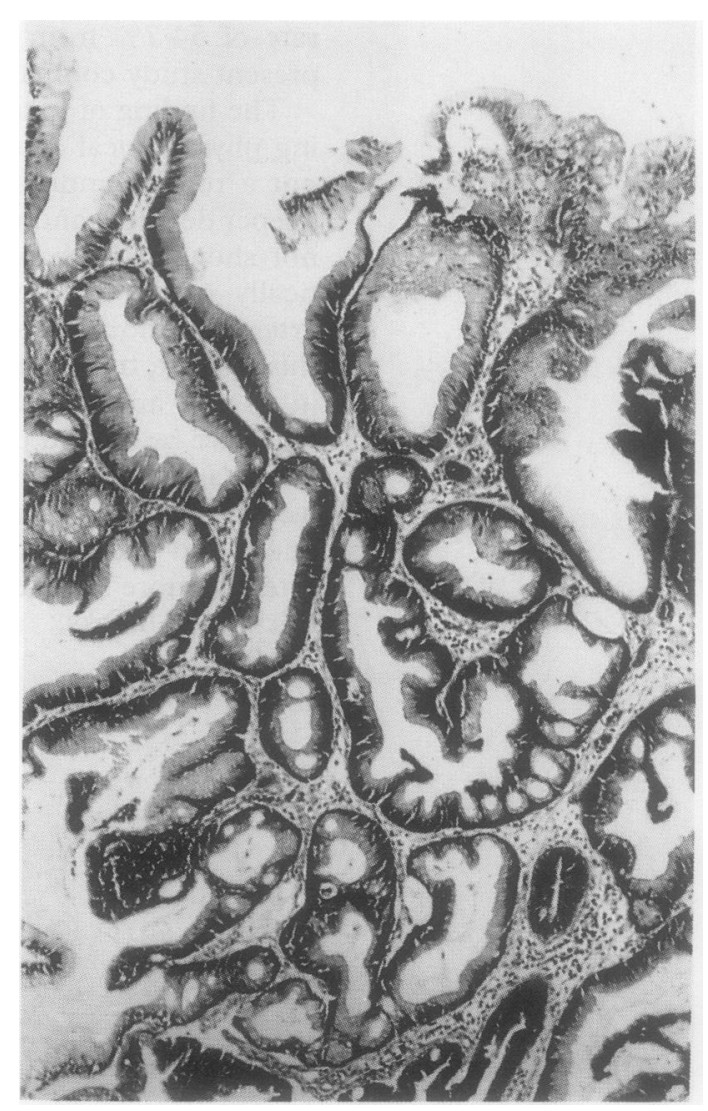

Figure 1 Finger-like villi lined by a single layer of columnar mucin secreting cells (haematoxylin and eosin). 


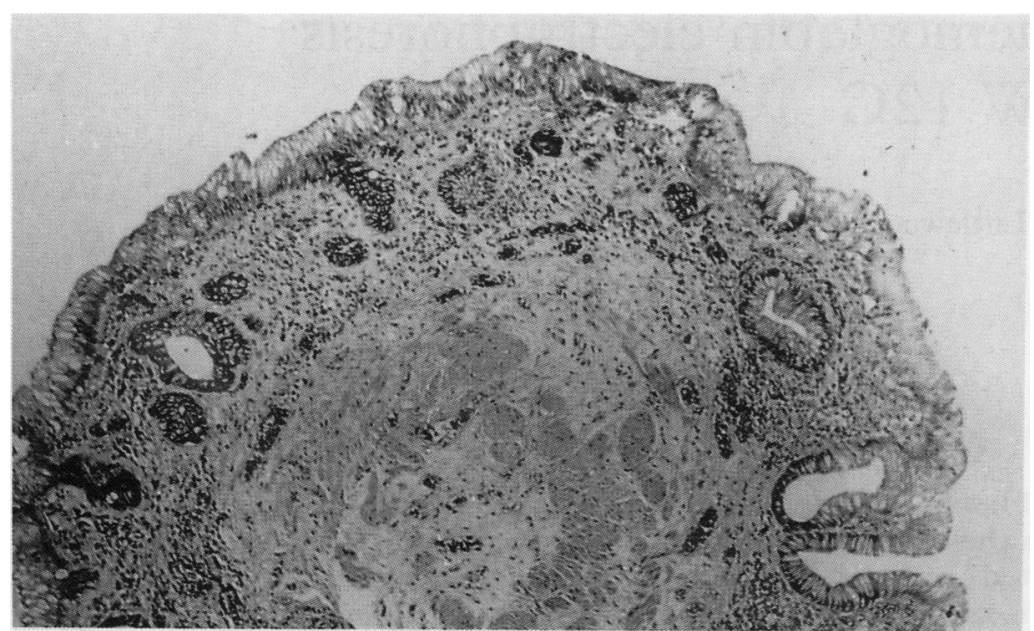

Figure 2 Atrophic small intestinal mucosa showing colonic metaplasia (haematoxylin and eosin).
There are no cases of adenomas developing at this site. There have been previous rare reports of villous adenomas arising in the bladder. ${ }^{910}$ These were thought to have arisen from metaplastic epithelium due to longstanding chronic irritation (cystitis glandularis). It has been suggested that the urinary stasis and chronic irritation of the intestinal mucosa produced by ileocystoplasties could predispose to the development of tumours at this site.

The ileal patch seen in the patient reported here has all of the features of colonic metaplasia as well as of the development of a tubulovillous adenoma, a lesion with possible malignant potential. No samples for urine cytology had been taken, but it is easy to see how lesions such as this could produce worrying and possibly misleading cytology.

The occurrence of a treatable lesion with possible malignant potential highlights the need for regular surveillance of these patients, and hence a greater likelihood of successful treatment.

The histological changes occurring in the intestinal mucosa from ileocystoplasties have been documented, and include villous atrophy and transmural chronic inflammation, resulting in an appearance of colonic metaplasia. The changes occurring in the ileal mucosa used in pelvic ileal pouch construction are similar. The evidence for colonic metaplasia is also substantiated by the demonstration of sulphated colonic-type mucin in the ileal mucosa of the pouches. ${ }^{1}$ The possibility of recurrent ulcerative colitis, epithelial dysplasia, and carcinoma occurring as complications of ileal pouches following ileo-rectal anastomosis has been raised. ${ }^{2}$ There have been two reports of tubular adenomas showing mild dysplasia arising in the ileal pouches of patients with familial adenomatous polyposis. ${ }^{1}$

To date, six cases of carcinoma have been reported arising in the ileal patch, or at the ileo-vesical junction 14 to 29 years after ileocystoplasty. These included three adenocarcinomas, $^{34}$ a signet ring carcinoma, ${ }^{5}$ and two transitional cell carcinomas. ${ }^{36}$ One case of an undifferentiated sarcoma arising at this site has also been reported. ${ }^{7}$ An adenocarcinoma arising in the adjacent bladder mucosa following an ileocystoplasty has also been recorded. ${ }^{8}$

Shepherd NA, Jass JR, Duval I, Moskowitz RL, Nicholls RJ. Restorative proctocolectomy with ileal reservoir: pathological and histochemical study of mucosal biopsy specimens. F Clin Pathol 1987;40:601-7.

We are very grateful to Miss A Tinker for typing this manuscript.

2 Shepherd NA. The pelvic ileal reservoir: apocalypse later? $B r$ Med $\mathcal{F} 1990 ; 301: 886-7$.

3 Stone AR, Davies N, Stephenson TP. Carcinoma associated with augmentation cystoplasty. $\mathrm{Br} f$ Urol 1987;60: 236-8.

4 Kawamura S, Takata K, Yoshida I, Seino K. A rare case of adenocarcinoma of the bladder following ileocystoplasty. Hinyokika-Kiyo 1987;33:1455-8.

5 Takasaki E, Murahashi I, Toyoda M, Honda M, Waku S. Signet ring adenocarcinoma of ileal segment following ileocystoplasty. $\mathcal{F}$ Urol 1983;130:562-3.

6 Smith P, Hardy GJ. Carcinoma occurring as a late complication of ileocystoplasty. Br 7 Urol 1971;43:576-9.

7 Egbert B, Kersten Kraft J, Perkash I. Undifferentiated sarcoma arising in an augmented ileocystoplasty patch. $\mathcal{f}$ Urol 1980;123:272-3.

8 Hasegawa S, Ohshima S, Kinukawa T, et al. Adenocarcinoma of the bladder 29 years after ileocystoplasty. $\mathrm{Br} \mathcal{F}$ Urol 1988;61:162.

9 Assor D. A villous tumour of the bladder. $f$ Urol 1978; 119:287-8.

10 Miller DC, Gang DL, Gavris V, Alroy J, Ucci AA, Parkhurst EC. Villous adenoma of the urinary bladder: A morphologic or biologic entity? Am f Clin Pathol 1983; 79:728-31. 